\title{
KAJIAN HACCP (Hazard Analysis and Critical Control Point) PENGOLAHAN JAMBU BIJI DI PILOT PLANT SARI BUAH UPT. B2PTTG - LIPI SUBANG
}

\author{
The Study of HACCP (Hazard Analysis and Critical Control Point) Guava Fruit Processing in Pilot Plant Fruits \\ Processing, UPT. B2PTTG - LIPI Subang
}

\section{Diki Nanang Surahman, Riyanti Ekafitri}

\author{
Balai Besar Pengembangan Teknologi Tepat Guna (B2PTTG), Lembaga Ilmu Pengetahuan Indonesia (LIPI), \\ Jl. K.S. Tubun No. 5 Subang, Jawa Barat 41213 \\ Email: diki.lucky@gmail.com
}

\begin{abstract}
ABSTRAK
Buah jambu biji mempunyai kandungan vitamin $\mathrm{C}$ dan beta karoten yang berkhasiat sebagai antioksidan dan dapat meningkatkan daya tahan tubuh. Salah satu pemanfaatan buah jambu biji adalah dengan mengolahnya menjadi sari buah. Pilot plant UPT. B2PTTG-LIPI Subang merupakan salah satu model pengolahan buah jambu biji menjadi sari buah. Dalam pengoperasiannya dibutuhkan penerapan HACCP untuk meningkatkan kualitas dan keamanan produk sari buah. Oleh karena itu dilakukan kajian HACPP. Kajian HACCP dilakukan menggunakan Panduan Penyusunan Rencana HACCP dengan proses penyusunannya mengikuti 7 prinsip sistem HACCP yang direkomendasikan oleh Standar Nasional Indonesia. Hasil kajian menunjukkan bahwa yang ditetapkan sebagai CCP adalah proses sortasi dan pencucian (untuk menghilangkan bahaya pada bahan baku jambu biji), proses sterilisasi dan pengisian merupakan CCP untuk produk jadi (sari buah jambu biji). Keseluruhan CCP ini harus mendapatkan pengawasan optimal antara lain: penanganan bahan baku, kontrol kebersihan operator, penggunaan air yang sesuai dengan persyaratan, dan memastikan kecukupan panas saat sterilisasi sari buah. Dalam pelaksanaannya, proses verifikasi sangat penting untuk dilakukan agar dapat mengetahui efektifitas penerapan HACCP. Penerapan HACCP yang sesuai diharapkan akan meningkatkan kualitas dan keamanan produk sari buah jambu biji.
\end{abstract}

Kata kunci: Sari buah, jambu biji, HACCP

\begin{abstract}
Guava has vitamin $\mathrm{C}$ and beta carotene that potent as antioxidant and can increase endurance. Guava can be processed into juice as a final product. UPT . B2PTTG-LIPI Subang has a Pilot Plant. The pilot plant itself is a model of processing fruit into juice. The processing of guava juice from the pilot plant needs an application of HACCP to improve the quality and safety of fruit juice products. The studies of HACCP uses the 7 principles of HACCP system recommended by the Indonesian National Standard. The result of studies showed that the set as CCP's are sortation and washing (for raw materials is the guava fruit), meanwhile sterilization and filling process are CCP's for guava juice/final product. All the CCP's should always be controlled and obtain optimal control by handling of raw materials, hygiene control operators, the use of water in accordance with the requirements of, and ensure the adequacy of current heat sterilization juice. In practice, the process of verification is very important to be done in order to determine the effectiveness of the implementation of HACCP. Appropriate application of HACCP is expected to improve the quality and safety of guava juice.
\end{abstract}

Keywords: Juice, guava, HACCP 


\section{PENDAHULUAN}

Buah jambu biji merupakan buah yang banyak digemari oleh masyarakat Indonesia. Buah jambu biji diketahui mempunyai kandungan vitamin $\mathrm{C}$ dan beta karoten sehingga dapat berkhasiat sebagai antioksidan dan meningkatkan daya tahan tubuh (Riana, 2000; Pdpersi, 2004). Menurut Rahmat dkk. (2006) kandungan jambu biji dalam 100 gram adalah vitamin A $792 \mathrm{IU}$, vitamin B1 0,05 mg, vitamin C 183,5 $\mathrm{mg}$, vitamin $\mathrm{E} 1,12 \mathrm{mg}$, asam folat $14 \mathrm{mcg}$, mineral seperti kalsium $20 \mathrm{mg}$, fosfor $25 \mathrm{mg}$, besi $0,31 \mathrm{mg}$, seng $0,23 \mathrm{mg}$, CU $0,103 \mathrm{mg}$ selenium $0,6 \mathrm{mg}$, senyawa fenolik seperti $\beta$-karoten $374 \mu \mathrm{g}$ dan likopen $5204 \mu \mathrm{g}$. Melihat dari kandungan nutrisi jambu biji tersebut diatas dan juga manfaat yang dihasilkan oleh buah jambu biji, maka buah ini berpotensi untuk dikembangkan menjadi bahan baku industri olahan pangan selain untuk dikonsumsi secara segar. Salah satu pemanfaatan buah jambu biji yang jumlahnya melimpah saat panen raya adalah dengan mengolah buah jambu biji menjadi sari buah sebagai produk akhir.

Aspek mutu dan keamanan pangan merupakan masalah utama dalam produksi dan pemasaran buahbuahan (Widaningrum dan Winarti, 2007). Secara spesifik dapat disebutkan bahwa buah-buahan Indonesia umumnya mempunyai masalah dalam hal mutu yang tidak konsisten dan mengandung kontaminan. Padahal, jaminan keamanan pangan merupakan suatu keharusan karena pangan termasuk kebutuhan dasar yang paling penting dan sangat esensial dalam kehidupan manusia. Oleh karena itu dalam industri pengolahan makanan dan minuman, penerapan sistem keamanan pangan yang meliputi: cara produksi makanan yang baik (GMP), sanitasi dan HACCP memiliki peranan yang sangat penting. Hal ini bertujuan untuk mencegah terjadinya keracunan dan penyakit yang diakibatkan oleh makanan atau minuman. Menurut Winarno (2002), lebih dari 90\% terjadi penyakit diakibatkan oleh makanan yang terkontaminasi mikrobiologi (food born deseases).

Salah satu model pengolahan buah biji jambu menjadi sari buah adalah Pilot Plant UPT. B2PTTG-LIPI Subang. Pilot plant pengolahan sari buah jambu biji sudah mulai beroperasi sejak tahun 1986. Pilot plant yang memiliki luas bangunan yaitu $450 \mathrm{~m}^{2}$ dengan peralatan lengkap dengan bahan logam stainless hibah dari negara Italia dengan pabrikasi peralatan di Bertuzzi, Italia. Kapasitas untuk satu lini produksi pengolahan sari buah mencapai maksimal 1000 - 2000 liter per hari. Namun yang sekarang digunakan hanya 600 - 1000 liter per hari, dengan salah satu varian sari buah yang diproduksi yaitu jambu biji.

Seiring dengan tuntutan akan produk yang aman dan memiliki kulitas yang baik, maka Pilot Plant ini telah menerapkan sistem GMP (Good Manufacturing Practices), namun belum memiliki sistem analisa resiko bahaya yang mungkin timbul pada setiap tahapan produksi yaitu HACCP (Hazard Analysis Critical Control Points). HACCP merupakan suatu piranti (sistem) yang digunakan untuk menilai bahaya dan menetapkan sistem pengendalian yang memfokuskan pada pencegahan (Muhandri dan Kadarisman, 2008). Salah satu alasan mengenai pentingnya penerapan sistem HACCP pada industri pangan adalah karena bahan-bahan yang digunakan serta selama proses produksi memiliki peluang terjadinya pencemaran yang dapat membahayakan konsumen. Pencemaran tersebut dapat berupa pencemaran fisik, kimia, maupun mikrobiologi. HACCP dapat diterapkan pada seluruh rantai pangan dari produk primer sampai pada konsumsi akhir dan penerapannya harus dipandu oleh bukti secara ilmiah terhadap resiko kesehatan manusia (BSN,1998).

Kajian ini bertujuan untuk mengidentifikasi titik-titik bahaya yang terdapat pada bahan baku yang digunakan dan tahapan proses pengolahan sari buah jambu biji dengan menggunakan tujuh prinsip HACCP sehingga proses produksi dapat dikendalikan dan menghasilkan produk yang bermutu.

\section{METODE PENELITIAN}

Kajian ini dilakukan pada tahun 2013 terhadap Pilot plant sari buah jambu biji di UPT-B2PTTG LIPI, Subang, Jawa Barat. Studi HACCP pada proses produksi sari buah jambu biji skala pilot ini menggunakan Panduan Penyusunan Rencana HACCP (BSN-Pedoman 1004-1999), daftar bahan baku dan bahan penunjang, bagan alir proses produksi, tabel penentuan tingkat resiko dan $C C P$ decision tree. Sedangkan proses penyusunannya, mengikuti 7 prinsip sistem HACCP yang direkomendasikan oleh Standar Nasional Indonesia (1998) yang dikeluarkan oleh BSN (1999), meliputi:

1. Prinsip 1: Analisis bahaya dan pencegahannya

2. Prinsip 2: Identifikasi Critical Control Points (CCP) di dalam proses

3. Prinsip 3: Menetapkan batas kritis untuk setiap CCP

4. Prinsip 4: Menetapkan cara pemantauan CCP

5. Prinsip 5: Menetapkan tindakan koreksi

6. Prinsip 6: Menyusun prosedur verifikasi

7. Prinsip 7: Menetapkan prosedur pencatatan (dokumentasi)

Analisis bahaya dilakukan dengan cara mendaftarkan semua bahaya yang mungkin terdapat dalam bahan baku dan tahap proses dengan mengacu pada referensi yang terkait (jurnal, buku, dokumen standarisasi dan hasil penelitian lainnya). Bahaya-bahaya yang teridentifikasi kemudian ditabulasikan ke dalam sebuah tabel disertai sumber bahaya, tingkat resiko dan tindakan pencegahannya. Tingkat resiko ditentukan berdasarkan seberapa besar akibat yang akan 
ditimbulkan oleh suatu bahaya dan seberapa sering bahaya tersebut kemungkinan terjadi. Setiap tahapan proses ditentukan termasuk CCP atau tidak melalui pertimbangan tingkat resiko dan berdasarkan jawaban atas pertanyaan dari CCP decision tree. Tahap proses yang tidak termasuk CCP, dapat termasuk control point (CP) yang berarti tahapan tersebut apabila tidak dikendalikan dengan baik dapat menyebabkan kecacatan dari segi kualitas (Widaningrum dan Winarti 2008).

\section{HASIL DAN PEMBAHASAN}

\section{Deskripsi Produk}

Buah jambu biji (Psidium guajava L.) merupakan jenis buah tropis yang menjadi sumber vitamin $\mathrm{C}$ tinggi dalam bentuk asid askorbik, dengan jumlah yang lebih tinggi dibandingkan buah-buahan yang lain (Wachu, 2006). Buah jambu biji mengandung 3 hingga 6 kali lebih banyak vitamin $\mathrm{C}$ nya dibandingkan jeruk, 10-30 kali lebih banyak dibandingkan pisang. Jambu biji, menurut penelitian (Wachu, 2006), juga mengandung vitamin A dalam jumlah yang banyak. Jambu biji merah memiliki kandungan vitamin A lebih tinggi, sekitar 3,1 mg/100 g dibandingkan dengan jambu biji berwarna putih. Buah ini dapat dikonsumsi secara segar atau diolah menjadi sari buah. Sari buah adalah minuman ringan yang dibuat dari sari buah dan air minum dengan atau tanpa penambahan gula dan bahan tambahan makanan yang diizinkan (BSN ,1995). Produk sari buah minimal harus memiliki 30\% bubur buah segar (pulp). Adapun deskripsi produk sari buah jambu biji yang diproduksi oleh Pilot Plant Pengolahan Sari Buah Bertuzzi di B2PTTG - LIPI dapat dilihat pada Tabel 1.

\section{Diagram Alir Proses Pengolahan Sari Buah Jambu Biji}

Diagram alir proses merupakan suatu urutan tahapan kerja dalam proses produksi pembuatan sari buah jambu biji dapat dilihat pada Gambar 1.

Tabel 1. Deskripsi produk sari buah jambu biji

\begin{tabular}{lll}
\hline Kriteria & Keterangan & \\
\hline Nama produk & Sari buah jambu biji & $\pm 50-60 \% \mathrm{v} / \mathrm{v}$ \\
Nama merk dagang & Juz & Min. 30\% b/v \\
& Air & $10-12 \%$ \\
& Bubur buah (pulp) & $500 \mathrm{ppm}$ \\
Komposisi & Gula putih & $1000 \mathrm{ppm}$ \\
& CMC & $1 \mathrm{ml} / \mathrm{liter}$ \\
& Asam sitrat & $0,05-0,1 \mathrm{gram} / \mathrm{liter}$ \\
Pengemas primer & Essence Jambu Biji & $300 \mathrm{ppm}$ \\
Pengemasan sekunder & Pewarna makanan merk butterfly colour food & \\
Masa kadaluarsa & Pengawet (Na-Benzoate) & Cup plastik \\
Kondisi penyimpanan & Dus karton & \\
Tujuan konsumen & 6 bulan & Suhu ruang $\left.\pm 27^{\circ} \mathrm{C}\right)$ \\
Cara penyiapan konsumsi & Umum & Dikonsumsi langsung \\
\hline
\end{tabular}




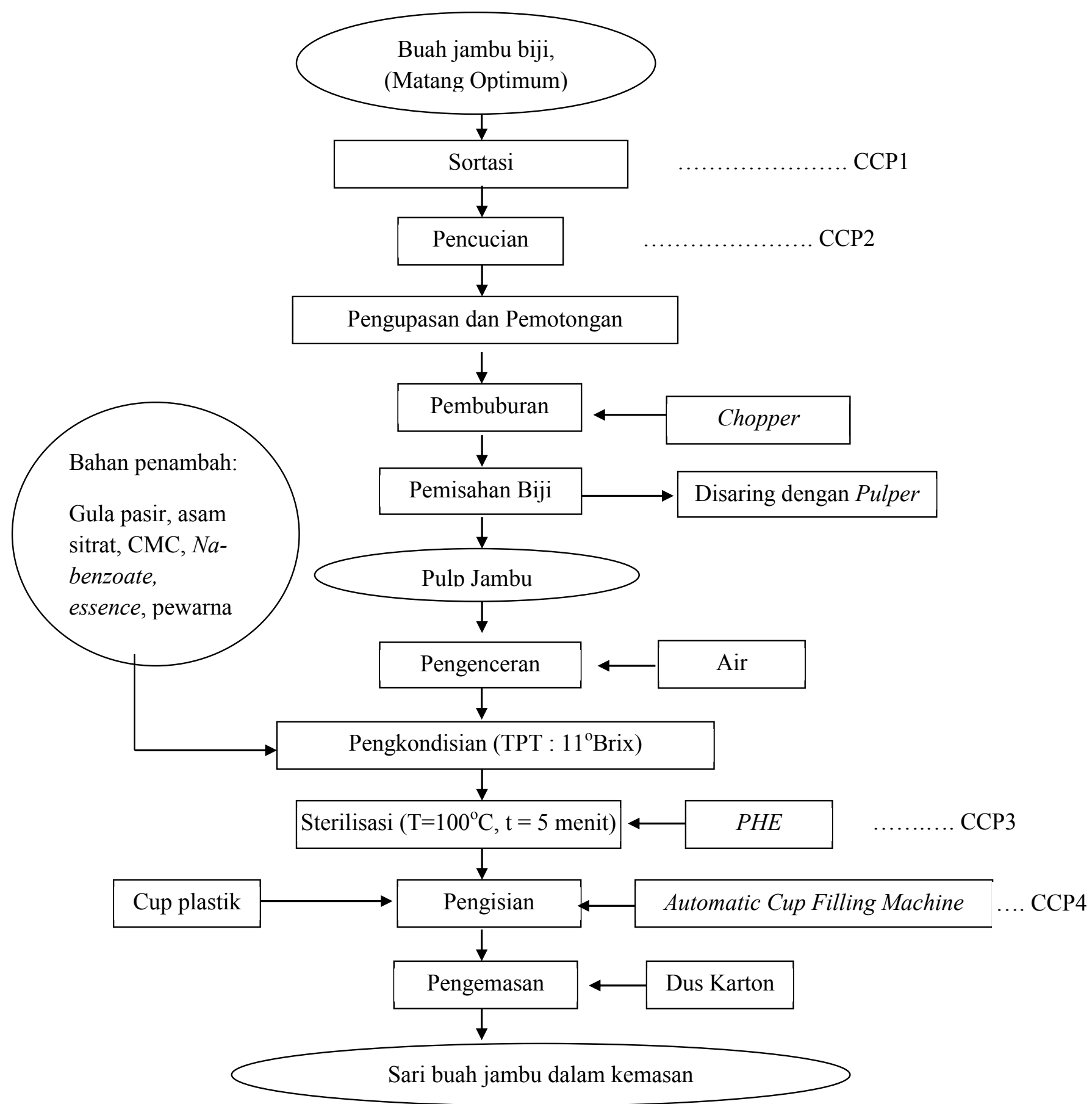

Gambar 1. Bagan alir proses produksi pembuatan sari buah jambu biji 


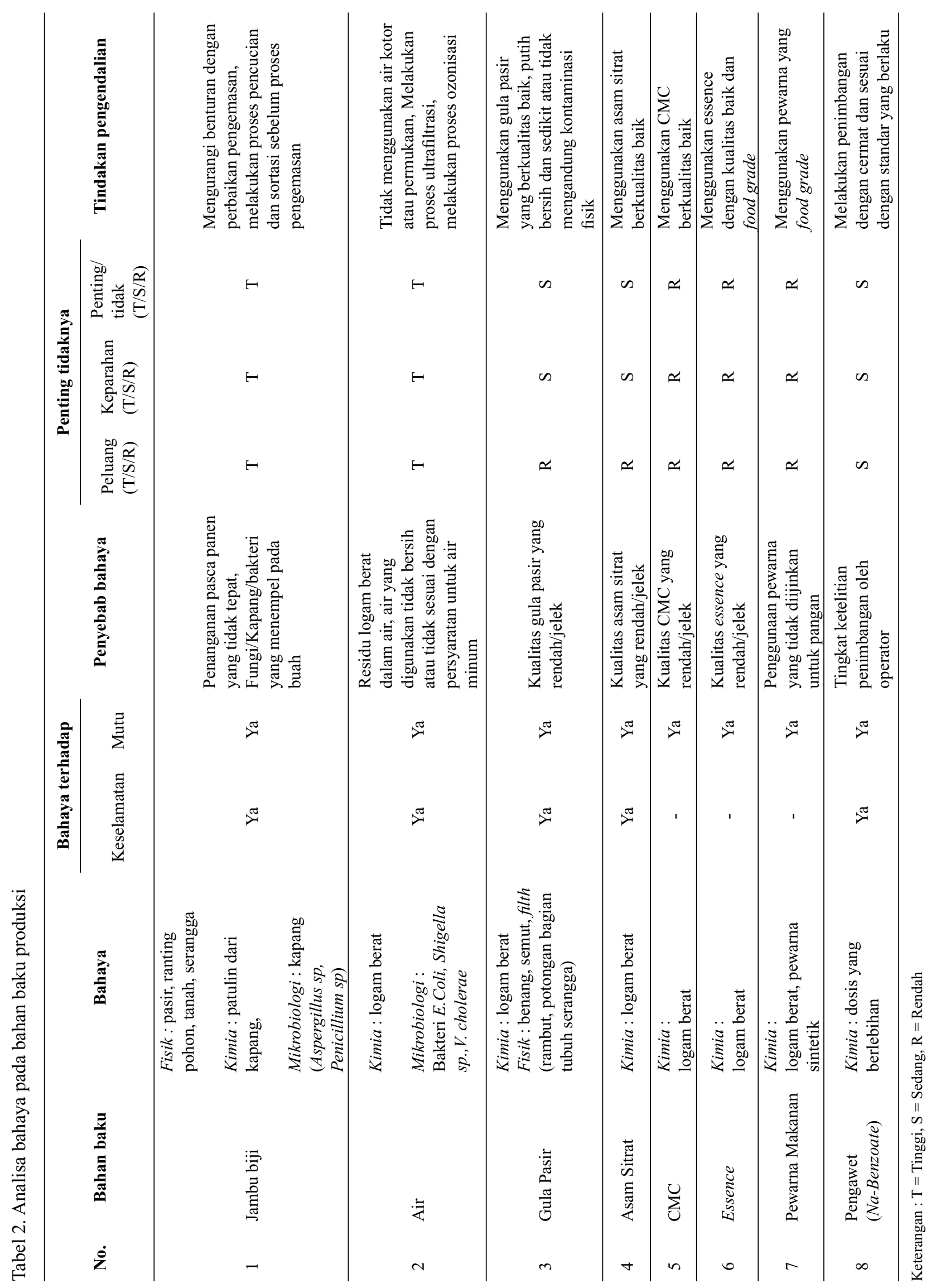




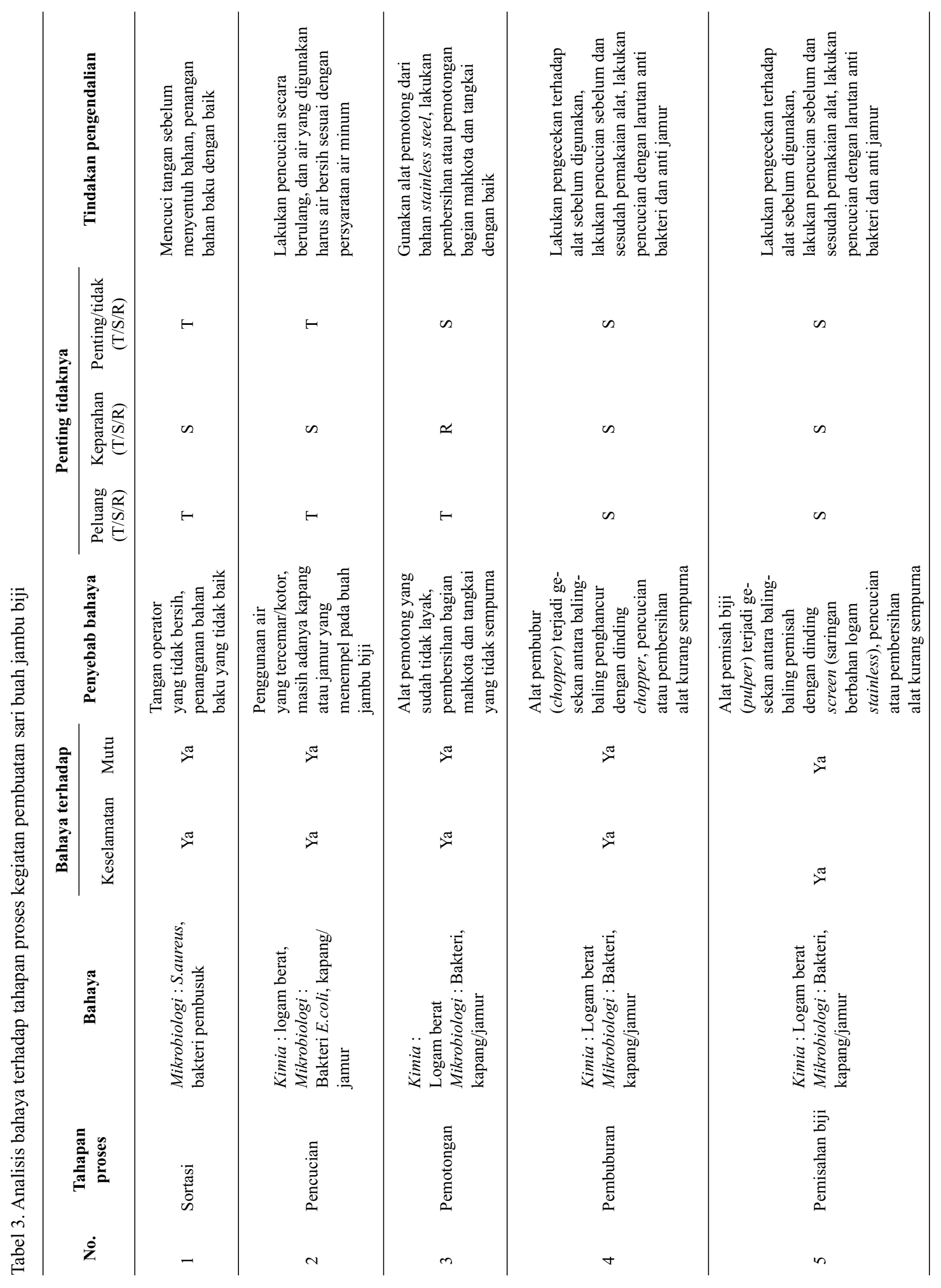




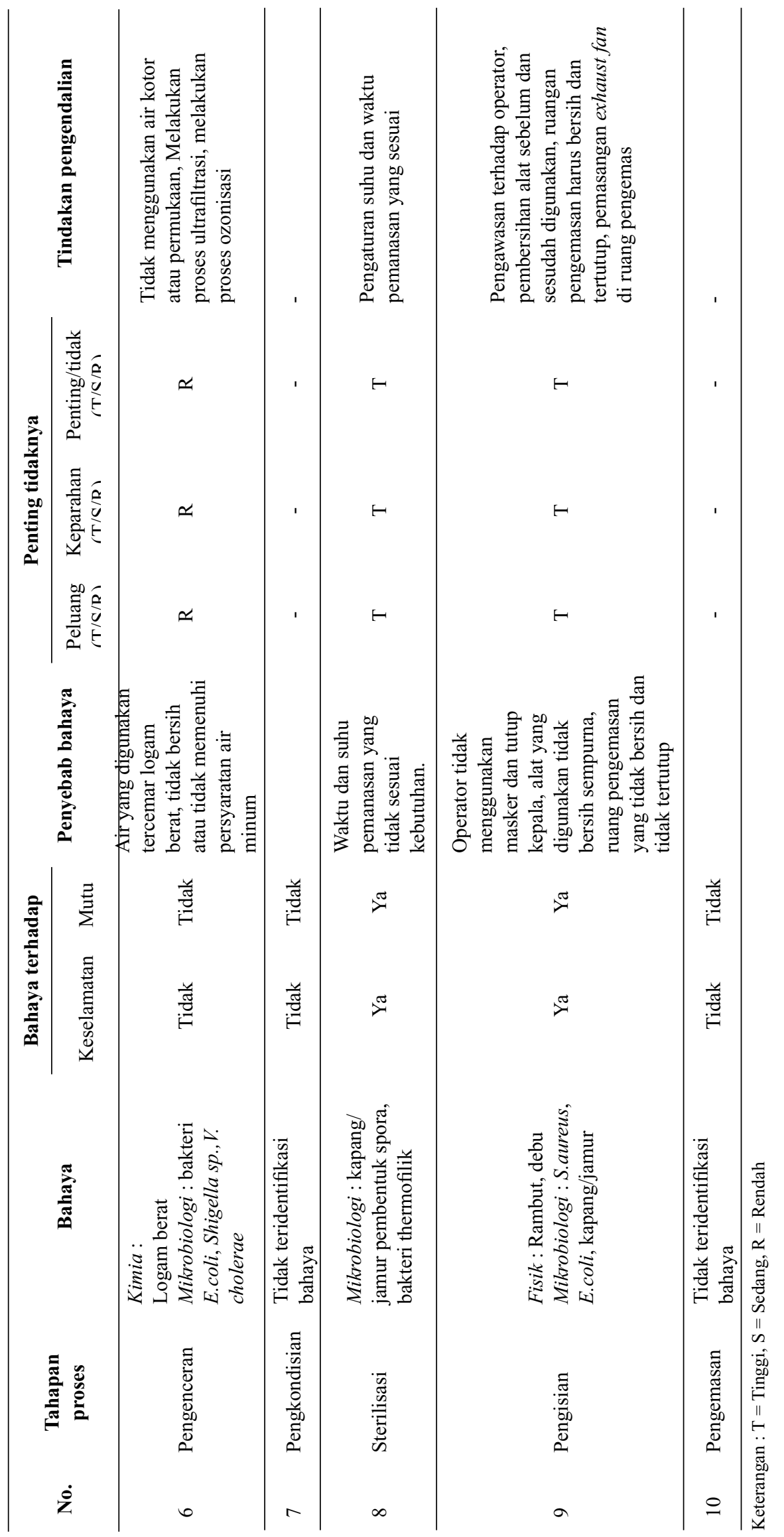




\section{Identifikasi Bahaya untuk Bahan Baku}

Proses pengolahan sari buah jambu biji menggunakan bahan baku buah jambu biji dan bahan tambahan pangan lain, yaitu CMC sebagai bahan penstabil, asam sitrat sebagai bahan pengasam, Na-Benzoate sebagai pengawet, gula pasir sebagai pemanis, essence jambu biji sebagai penguat aroma/flavor, pewarna makanan sebagai penguat warna. Air digunakan dalam proses pencucian buah jambu biji dan sebagai pengencer. Bahaya-bahaya yang teridentifikasi pada bahan baku seperti disajikan pada Tabel 2 .

Bahan baku buah jambu biji mengandung bahaya mikrobiologi yang berasal dari jamur yang menempel pada buah jambu terutama dalam kondisi lembab. Jamur buah biji jambu yang banyak ditemui adalah Aspergillus sp menghasilkan mikotoksin patulin. Mikotoksin merupakan senyawa organik beracun hasil metabolisme sekunder dari kapang (fungi, jamur, cendawan). Senyawa tersebut dapat mengganggu kesehatan manusia dan hewan dengan berbagai bentuk perubahan klinis dan patologis (BSN, 2009). Mikotoksin perlu dikendalikan melalui penanganan prapanen sampai pascapanen (Miskiyah, dkk, 2010). Konsumsi produk pangan yang terkontaminasi mikotoksin dapat menyebabkan terjadinya mikotoksikosis, yaitu gangguan kesehatan pada manusia dan hewan dengan berbagai bentuk perubahan klinis dan patologis, misalnya dapat menyebabkan penyakit kanker hati, degenerasi hati, demam, pembengkakan otak, ginjal, dan gangguan syaraf (Rahayu2006). Oleh karena itu bahaya cemaran pada buah jambu biji dapat dikendalikan dan dihilangkan melalui tahapan CCP yaitu sortasi dan pencucian.

Bahan baku yang lainnya adalah air. Mutu air yang digunakan untuk proses pengolahan harus memiliki mutu seperti mutu air minum (Deptan, 2000). Menurut Buckle (1987), air minum harus bersih dan jernih, tidak berwarna, tidak berbau, dan tidak mengandung bahan tersuspensi atau kekeruhan. Sedangkan menurut Soekarto (1990), persyaratan air minum yang terpenting adalah harus bebas dari bakteri dan senyawa kimia yang berbahaya serta tidak berwarna, tidak berbau, tidak menimbulkan rasa aneh dan tidak keruh. Menurut Permenkes No. 416/Menkes/Per/IX/1990 disebutkan bahwa jumlah total coliform pada air sumur (sumur bor) adalah 0/ 100 ml. Air digolongkan sebagi bahan baku yang memiliki tingkat resiko yang tinggi dan peluang keparahan yang tinggi sehingga perlu dikendalikan melalui tahapan CCP pada proses sterilisasi. Dalam proses pembuatan sari buah biji jambu, digunakan air yang sudah mengalami ozonisasi dan ultrafiltrasi sehingga terbebas dari kontaminasi kimia maupun mikrobiologi.

Bahan baku selanjutnya adalah gula pasir. Cemaran yang diidentifikasi pada bahan baku ini dalah cemaran kimia, yaitu keberadaan logam berat dan cemaran fisik yang dapat berupa benang, semut, filth (rambut, potongan bagian tubuh serangga). Menurut Casmin (2003), cemaran kimia pada gula pasir dapat berupa keberadan belerang dioksida. Haryadi (2001), menyatakan bahwa cemaran kimia umumnya tidak dapat dikurangi atau dihilangkan selama pegolahan. Cemaran kimia hanya dapat ditekan seminimal mungkin melalui spesifikasi dan pengawasan bahan baku yang ketat terhadap penyedia bahan baku. Sedangkan untuk meminimalisir adanya cemaran fisik dapat dilakukan dengan menggunakan gula pasir yang berkualitas baik, sedikit, atau tidak mengandung kotoran terutama kontaminan fisik. Dapat pula melakukan tindakan pengayakan atau penyaringan sebelum penggunaan gula pasir pada proses pengkondisian.

Bahan tambahan pangan yang digunakan pada pembuatan sari buah jambu biji antara lain asam sitrat, $\mathrm{CMC}$, essence, pewarna makanan, dan bahan pengawet ( $\mathrm{Na}$ benzoat). Menurut Munaro (2002), asam sitrat berfungsi untuk memberikan cita rasa asam, menurunkan $\mathrm{pH}$ bahan, dan berperan sebagai chelating dan sequestering agent. Pada pembuatan sari buah jambu biji ini asam sitrat berfungsi untuk memberikan sedikit cita rasa asam dan menurunkan pH sehingga dapat meningkatkan daya awet produk. Hal ini dikarenakan pada $\mathrm{pH}$ rendah, beberapa mikroba perusak tidak dapat bertahan hidup. CMC sebagai bahan penstabil untuk mencegah terbentuknya endapan di dasar sari buah. Essence ditambahkan untuk memperkuat cita rasa sari buah jambu biji, pewarna makanan diberikan untuk mempertegas warna sari buah pada produk akhir, dan $\mathrm{Na}$ - benzoat ditambahkan sebagai bahan pengawet. Cemaran yang diidentifikasi pada bahan tambahan ini antara lain cemaran kimia berupa logam berat dan penggunaan dosis secara berlebihan. Oleh karena itu harus dihindari penggunaan bahan tambahan pangan dengan kualitas yang rendah. Penggunaan asam sitrat, $\mathrm{CMC}$, essence, pewarna makanan, dan bahan penggawet harus yang memiliki kualitas yang baik. Pada penggunaan pewarna makanan dapat menjadi bahaya kimia apabila pewarna makanan yang digunakan adalah pewarna makanan yang tidak diizinkan untuk makanan (misalnya pewarna tekstil) yang dapat mengakibatkan pengaruh yang buruk bagi kesehatan konsumen. Begitu pula penggunaan Na-benzoat sebagai bahan pengawet. Penggunaan Na-benzoat harus sesuai dengan batas penggunaan yang diperbolehkan. Penggunaan Na-benzoat yang diizinkan adalah maksimal 600 ppm (Peraturan Menkes No. 722/Menkes/Per/IX/88). Tindakan pengendalian yang dapat dilakukan adalah melakukan penimbangan yang teliti dan seksama sehingga bahan pengawet yang ditambahkan pada produk tepat sesuai dosis tidak berlebihan.

\section{Penetapan CCP untuk Pengendalian (Prinsip 2)}

Identifikasi bahaya proses yang dhasilkan pada proses pembuatan sari buah jambu biji (Tabel 3), selanjutnya dilakukan penentuan CCP, batas kritis, tindakan pemantauan 
dan tidakan koreksi (Tabel 4) yang merupakan prinsip 3, 4, dan 5 dalam sistem HACCP.

Proses pertama dalam pembuatan sari buah biji jambu adalah sortasi (CCP 1). Kegiatan ini berfungsi untuk memisahkan segala cemaran fisik dan biologi yang ada pada buah jambu, seperti tanah, batu, kerikil, daun, serangga, dan lain-lain. Sortasi juga dilakukan untuk memisahkan buah yang sudah busuk, mengandung kapang, dan buah yang rusak/lunak karena benturan dengan buah yang masih bagus. Bahaya yang diidentifikasi pada tahapan ini adalah bahaya mikrobiologi yaitu adanya $S$. aureus atau bakteri pembusuk yang berasal dari penanganan bahan baku yang tidak baik atau kontamitasi tangan operator. Manusia yang sehat saja merupakan sumber mikroba seperti Streptococcus dari kotoran dan Staphylococcus dari kulit, hidung, mulut dan tenggorokan. Setiap kali tangan pekerja kontak dengan bagian-bagian tubuh yang mengadung mikroba patogen, maka tangan tersebut akan terkontaminasi dan ketika tangan kontak dengan makanan, kontaminasi segera terjadi. Kontaminasi juga terjadi melalui udara dari pernapasan, mulut, dan juga dari pakaian. Proses sortasi ini dinilai memiliki tingkat keparahan yang sedang, dengan tindakan pengendalian berupa penanganan bahan baku yang baik dan menjaga kebersihan operator saat melakukan tahapan ini.

Tahapan kedua setelah sortasi adalah pencucian (CCP 2). Tahapan ini diidentifikasi dapat membawa bahaya kimia berupa logam berat dan bahaya mikrobiologi berupa bakteri E. coli dan kapang. Kedua bahaya ini dapat muncul dari penggunaan air yang tercemar dan masih adanya kapang atau jamur yang menempel pada buah jambu biji. Tingkat keparahan dari bahaya ini dinilai sedang dan digolongkan sebagai CCP. Tindakan pengendalian yang dapat dilakukan adalah pencucian buah secara berulang dan air yang digunakan harus air bersih sesuai dengan persyaratan air minum. Menurut Soekarto (1990) persyaratan air minum yang terpenting adalah harus bebas dari bakteri dan senyawa kimia yang berbahaya serta tidak berwarna, tidak berbau, tidak menimbulkan rasa aneh dan tidak keruh. Menurut Permenkes No. 416/Menkes/ Per/IX/1990 disebutkan bahwa jumlah total coliform pada air sumur (sumur bor) adalah 0/100 ml. Air yang digunakan pada pengolahan sari buah biji jambu ini adalah air sumur bor yang sudah di hilangkan bakterinya secara ozonisasi dan ultrafiltasi.

Tahapan selanjutnya adalah pemotongan. Tahapan ini memiliki resiko bahaya kimia berupa logam berat yang dapat berasal dari pisau pemotong dan bahaya mikrobiologi berupa kapang/ jamur yang dapat berasal dari pembersihan makota dan tangkai buah jambu biji yang tidak sempurna. Tahapan ini dinilai memiliki tingkat keparahan yang rendah. Tindakan pengendalaian yang dapat dilakukan adalah dengan menggunakan alat pemotong yang bersih, tidak berkarat, dan terbuat dari logam stainless. Selain itu perlu penghilangan bagian mahkota dan tangkai yang sempurna.
Setelah pemotongan dilakukan pembuburan dan pemisahan biji. Kedua tahapan ini menggunakan alat chopper. Resiko bahaya yang diidentifikasi adalah cemaran kimia dan mikrobiologi. Cemaran kimia dapat berasal dari gesekan antara baling-baling penghancur pada chopper dengan dinding chopper. Cemaran mikrobiologi dapat berasal dari kontaminasi silang bila chopper tidak dibersihkan sempurna. Hal ini dapat diatasi dengan pembersihan dan pencucian setiap bagian chopper menggunakan larutan anti bakteri dan anti jamur yang direkomendasikan untuk produk pangan.

Setelah dilakukan pemisahan biji, dilakukan pengenceran.Penambahanairsaatpengenceraninidiidentifikasi memiliki tingkat keparahan yang rendah, cemaran-cemaran pada proses ini sudah diatasi melalui proses selanjutnya. Air yang digunakan pada proses pengenceran, harus air yang memenuhi persyaratan air minum. Pada pengolahan sari buah jambu biji di UPT. B2PTTG digunakaan air yang telah mengalami proses ultrafiltrasi dan ozonisasi. Selanjutnya dilakukan proses pengkondisian yaitu penambahan bahan tambahan pangan dan pencampuran sari buah dengan gula pasir yang dilakukan dalam tangki homogenizer.

Tahapan selanjutnya adalah sterilisasi (CCP 3). Tahapan ini merupakan tahapan yang diidentifikasi memilili resiko bahaya dan tingkat keparahan yang tinggi. Hal ini terkait dengan kecukupan panas yang diterima sari buah sehingga dapat membunuh mikroba patogen dan mikroba pembusuk. Suhu pemansan yang digunakan adalah $90-100^{\circ} \mathrm{C}$ selama 5-10 menit. Apabila suhu atau waktu sterilisasi yang dilakukan kurang dari suhu dan waktu yang telah ditetapkan, dikhawatirkan masih ada mikroba yang mencemari produk sehingga mempengaruhi kemanan pangan pada produk akhir. Oleh karena itu tahapan ini dinilai sebagai CCP.

Setelah mengalami sterilisasi dalam pipa yang langsung terhubung dengan mesin pengemas, sari buah biji jambu langsung terisi dalam kemasan plastik berukuran $220 \mathrm{ml}$. Pada tahap pengisian ini (CCP 4) diidentifikasi juga memiliki tingkat peluang bahaya dan keparahan yang tinggi. Hal ini dikarenakan dapat terjadinya kontaminasi fisik dan mikrobiologi. Kontaminasi fisik dapat berupa cemaran filth (rambut, potongan tubuh serangga, dan debu). Kontaminasi mikrobiologi dapat terjadi akibat kontaminasi silang antara sari buah dengan kemasan yang tidak bersih. Kedua kontaminasi dapat berasal dari ruang pengemas yang tidak bersih, tidak tertutup, dan operator yang bertugas untuk mengecekan apakah terdapat kebocoran kemasan atau tidak. Setelah proses pengemasan selesai, dilakukan proses pengepakan dan distribusi.

Berdasarkan uraian diatas, disimpulkan bahwa tahapan proses yang dikategorikan sebagai CCP adalah proses sortasi, pencucian, sterilisasi dan pengisian. Setiap tahapan proses yang termasuk CCP ini dapat dilihat pada Tabel 4. 


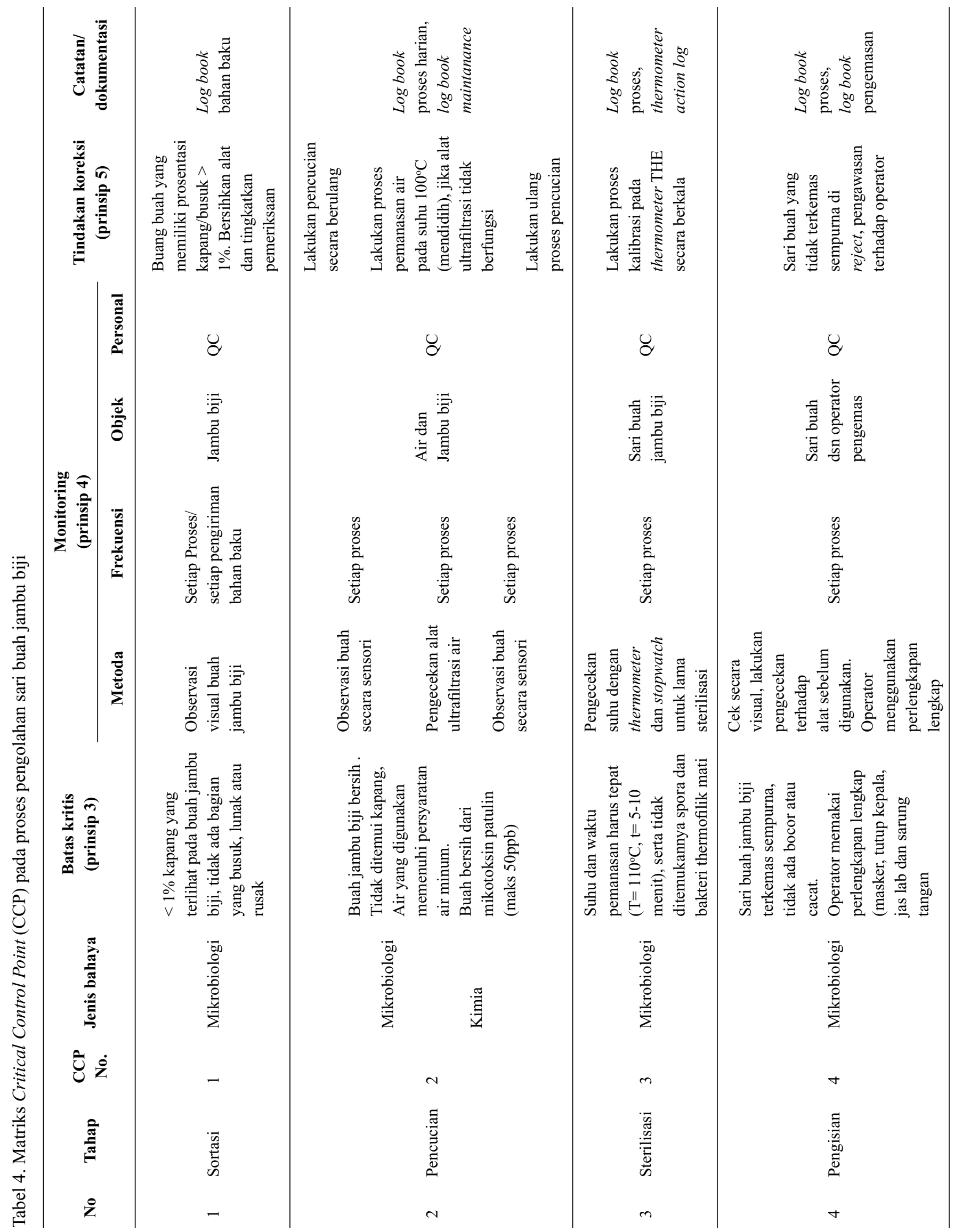




\section{Verifikasi dan dokumentasi (Prinsip 6 dan 7)}

Setelah analisis bahaya dan penetapan CCP selesai dilakukan dan telah didokumentasikan dalam rencana HACCP, maka tahap selanjutnya dilakukan penetapan prosedur verifikasi dan dokumentasi. Proses verifikasi dan dokumentasi dilakukan oleh B2PTTG bekerjasama dengan Dinas Kesehatan Kabupaten Subang - Jawa Barat yang bertujuan untuk memantau efektifitas penerapan HACCP pada pengolahan sari buah jambu biji. Proses verifikasi dapat dilakukan dengan menganalisa setiap tahapan prose sang diidentifikasi sebagai CCP. Dokumentasi dilakukan secara internal dan terkontrol.

\section{KESIMPULAN}

Hasil kajian HACPP terhadap produksi sari buah jambu biji di Pilot Plant Sari Buah B2PTTG menunjukkan bahwa yang ditetapkan sebagai CCP adalah proses sortasi, pencucian, sterilisasi dan pengisian. Oleh karena itu harus dilakukan penanganan bahan baku yang baik, kontrol kebersihan operator, penggunaan air yang sesuai dengan pesyaratan, dan memastikan kecukupan panas saat sterilisasi sari buah. Dalam pelaksanaannya, proses verifikasi sangat penting untuk dilakukan agar dapat mengetahui efektifitas penerapan HACCP. Penerapan HACCP yang sesuai diharapkan akan meningkatkan kualitas dan keamanan produk sari buah jambu biji.

\section{DAFTAR PUSTAKA}

Buckle, K.A., Edwads R.A., Fleet G.J. dan Wotton, M. (1987). Ilmu Pangan. Terjemahan oleh H. Purnomo dan Adiono. UI. Press, Jakarta.

Badan Standarisasi Nasional (1995). Sari Buah. SNI 01-37191995. BSN, Jakarta.

Badan Standarisasi Nasional (1998). Analisa Bahaya dan Pengendalian Titik Kritis. SNI 01-4852-1998. BSN, Jakarta.

Badan Standardisasi Nasional (1999). Pedoman Penyusunan Rencana Sistem Analisa Bahaya dan Pengendalian Titik Kritis (HACCP). BSN, Jakarta.

Badan Standarisasi Nasional (2009). Batas Kandungan Mikotoksin dalam Pangan. SNI 7385. BSN, Jakarta.

Casmin (2003). Kajian Aplikasi GMP, Sanitasi, dan Penyusunan Dokumen Rencana HACCP, Produk Minuman Sari Kelapa "PrimaCo" di PT. Halintar Bahana Prima Divisi Nata de Coco, Leuwikopo, Bogor. Skripsi. Fakultas Teknologi Pertanian. Institut Pertanian Bogor, Bogor.
Departemen Pertanian (2000). Pedoman Pelaksanaan Verifikasi Sistem HACCP. Pedoman Mutu No.07. Departemen Pertanian Republik Indonesia, Jakarta.

Haryadi, R.D. (2001). Sistem Analisa Bahaya dan Pengendalian Titik Kritis (HACCP). Makalah Trainning HACCP, Bogor.

Miskiyah, dkk. (2010). Kontaminasi mikotoksin pada buah segar dan produk olahannya serta penanggulangannya. Jurnal Litbang Pertanian 29: 3.

Murano, P.S. (2002). Understanding Food Science and Technology. Thomson Wadsworth, Australia.

Muhandri, T. dan Kadarisman, D.(2008). Sistem Jaminan Mutu Industri Pangan. IPB Press, Bogor.

Pdpersi (2004). Obat tradisional: jambu biji (Psidium guajava L.). http://www.pdpersi.co.id./pusat data\&informasi PERSI.htm. [ 22 Juni 2013].

Rahayu, W.P.(2006).Mikotoksin dan Mikotoksis: Mikrobiologi keamanan pangan. Departemen Ilmu dan Teknologi Pangan, Institut Pertanian Bogor.

Rahmat, A., Mohd, F.Z. dan Zarida, H. (2006). The effect of guava (Psidium Guajava) consumption on total antioxidant and lipid profile in normal male youth. African Journal of Food Agriculture Nutrition and Development 6:1-12.

Riana, A. (editor). (2000). Jambu biji. http://www. asiamaya. com/nutrients/jambubiji.htm. [22 Juni 2013].

Soekarto, S.(1990). Dasar-dasar Pengawasan dan Standardisasi Mutu Pangan. IPB Press, Bogor.

Wachu (2006). Penjualan meningkat setiap isu DBD merebak: jambu batu di sekitar Situ Ciburuy. Pikiran Rakyat 9 Maret 2006.

Widaningrum dan Winarti, C. (2008). Studi penerapan HACCP pada proses produksi sari buah apel. Makalah Puslitbang BSN, Jakarta.

Winarno, F.G. (2002). Cara berproduksi makanan yang baik. Makalah Trainning Auditor Sistem HACCP. M-brio Trainning, Bogor. 